\title{
Streets Apart: Does Social Capital Vary with Neighbourhood Design?
}

\author{
Lisa Wood, ${ }^{1}$ Billie Giles-Corti, ${ }^{2}$ and Max Bulsara ${ }^{3}$ \\ ${ }^{1}$ Centre for the Built Environment and Health, School of Population Health, The University of Western Australia, Perth, \\ WA 6009, Australia \\ ${ }^{2}$ McCaughey VicHealth Centre for Community Wellbeing, Melbourne School of Population Health, \\ University of Melbourne, Melbourne, VIC 3010, Australia \\ ${ }^{3}$ Institute of Health and Rehabilitation Research, University of Notre Dame Australia, Fremantle, Perth, WA 6959, Australia
}

Correspondence should be addressed to Lisa Wood, lisa.wood@uwa.edu.au

Received 7 February 2012; Revised 20 May 2012; Accepted 30 May 2012

Academic Editor: Annette Hastings

Copyright (C) 2012 Lisa Wood et al. This is an open access article distributed under the Creative Commons Attribution License, which permits unrestricted use, distribution, and reproduction in any medium, provided the original work is properly cited.

While neighbourhood differences in social capital have been mapped, few empirical studies have considered the nexus between specific physical characteristics of communities and social capital. In this study we hypothesised that social capital would be positively associated with a more walkable street network design, but inversely associated with negative experiences and perceptions of neighbourhood environments. Data was gathered through a random cross-sectional telephone survey of adults $(n=339)$ from three suburbs with differing street network design. Although there was some relationship between street network layout and social capital, this was not always as hypothesised by previous studies. Perceived incivilities, lower levels of trust and support were among factors that may have countered some of the positive influences of a walkable street network design on social capital. Overall, our findings suggest that the built environment may influence neighbourhood social capital at both a real and perceived level. While the actual presence and type of facilities, neighbourhood design and walkability may impact on social capital formation and maintenance, so too can perceptions of the physical and social environment. Understanding the complex intertwining of physical neighbourhood features, perceptions and social dynamics is relevant to growing public policy interest in strengthening social capital for enhanced community wellbeing.

“...things which we see are not by themselves what we see ..." Immanuel Kant

\section{Introduction}

Over the last two decades, social capital has engendered increasing political and social policy attention, and there has been a proliferation of literature across a range of disciplines, including sociology, psychology, economics, political sciences, anthropology, developmental studies, education, and health. While there are varying definitions, the common essence of these is well captured in the definition proffered by Cohen and Prusak, who define social capital as the stock of active connections among people such as the trust, mutual understanding, and shared values and behaviors that bind the members of human networks and communities and make cooperative action possible [[1], page 4].

One of the reasons for social capital's rapid rise to conceptual popularity seems to be that it imputes a "capital" or calculable value to those human aspects of community, organizations, policies, and family life that are sometimes overlooked, but are nonetheless vital to individual and collective wellbeing [2, 3]. Social capital seeks to capture something over and above the measurement of individual social connections [4], hence distinguishing it from concepts 
such as social support. It also draws attention to the mesolevel social structures of neighborhoods or other groups which are said to sometimes get lost between individual and broader social systems orientations [5].

While researchers and public policy makers concur that there is value in building and preserving social capital, far less is known about how to go about this. For instance, social capital has been shown to be influenced by sociodemographic characteristics of communities such as ethnic diversity [6], but such determinants are not readily or ethically amenable to intervention. However, a growing body of research suggests that other contextual aspects of a community's environment may shape social capital in a way that is not explained by demographic variables. For example, neighborhood differences in social capital have remained after adjusting for individual factors such as age, sex, marital status, race and socioeconomic factors such as income and education [7-9].

What does then help to account for observed area or neighborhood differences in social capital? The general tenor of the literature suggests that social capital is likely to be influenced by both the physical and social characteristics of a neighborhood, and by the interplay between the two. This parallels discourse around the dual and interactive effect of material, structural, and social facets of place on health [10]. While area differences in social capital are well documented $[8,9,11]$, few empirical studies to date have considered the nexus between specific physical characteristics of communities and social capital. Pioneering exceptions include the work of Macintyre and Ellaway in UK [12] and studies of the relationship between housing and social capital emanating from USA [13]. Neighborhood perceptions also appear to matter, as exemplified in research by Ziersch et al. [14] that found that favorable perceptions of a neighborhood (in terms of cleanliness and noise) were associated with neighborhood connections, trust, and safety. Conversely, negative perceptions of the physical or social environment, such as those relating to incivilities or crime, have a well-documented impact on sense of community [1517], but have been less explored explicitly in relation to social capital in research to date.

Social capital may also be influenced by the way in which the physical neighborhood environment is planned and designed. While sense of community is the concept most often linked to New Urbanism, there is some emerging interest in whether neighborhoods designed according to New Urbanist principles are conducive to social capital [1820]. More walkable and pedestrian oriented neighborhoods are one of the hallmarks of New Urbanism, a urban planning paradigm that grew out of concerns about the sustainability of post-WWII urban planning, characterized by disconnected streets, high vehicle dependency, segregated land use, and low residential density [21]. Based upon more traditional planning paradigms, the principles of New Urbanism aim to promote walking and sense of community by planning higher-density communities with interconnected grid-style streets and mixed land use [7, 22].

So how might a more walkable neighborhood design relate to social capital? The potential for unplanned or casual social interactions with neighbors and others while "out and about" is one mechanism, and this has found support in several studies. Lund, for example, found that residents who walked more within their neighborhoods were more likely to have unplanned interactions with neighbors and to develop social ties [23], whilst a more walkable environment and street network design was found by Leyden to promote neighborly interactions, and through this, the development of social capital [19]. Similarly, another study by Lund found that sense of community was higher among residents living in a "traditional design" neighborhood (which reflected New Urbanist principles of walkability), compared with residents living in a more automobile oriented suburb [24]. Walking to local destinations rather than driving not only increases the likelihood of social encounters, but could also contribute to social capital in a number of other ways, including increased familiarity with the neighborhood, which may in turn enhance the extent to which residents feel that they "belong" and feel connected to it. Seeing people out and about walking can also symbolically signal positive cues about the community ambience and safety of the neighborhood, a hypothesis that has been borne out in research into dog walking as a catalyst for strengthening community social fabric [25].

The potential impact of designing more walkable neighborhoods on the social fabric of communities is not merely of academic interest, as it converges with growing policy and intervention interest in how we can make our cities and suburbs more conducive to quality of life, livability, and environmental sustainability [26].

This study sought to build on and add to the work of Lund [23, 24] and Leyden [19] to empirically investigate social capital in three suburbs with differing street network design. While Leyden determined walkability subjectively, this study used objective measures of street connectivity and layout to categorize and select study suburbs, hypothesizing that the traditional neighborhood design (characterized by grid street networks) would provide a more walkable environment, which in turn would promote the development of social capital. The study also sought to build on Lund's observations about the importance of people's perceptions about their local environment [23]. In particular, we postulated that the mechanisms by which fear of crime and perceptions of safety have been shown to affect sense of community [27] may be transferable to social capital; if people are fearful, they may be less likely to go out of their home, use local facilities, attend clubs or functions, or interact with strangers or people they meet "in the street," particularly at night [28].

\section{Study Aims}

This study explored the potential associations between social capital, and the design and characteristics of the built environment in which people live. In this context, characteristics of the built environment include street network design and connectivity, perceived availability and adequacy of local facilities and amenities, and resident perceptions of 
safety, crime, suburban problems, and incivilities. This paper focuses on two specific hypotheses that were informed by our review of the literature and formative qualitative research (focus groups) undertaken in the three study suburbs:

$\left(\mathrm{H}_{1}\right)$ a more walkable neighborhood street network design is positively associated with social capital.

$\left(\mathrm{H}_{2}\right)$ Negative experiences and perceptions of the neighborhood environment are negatively associated with social capital.

\section{Methods}

3.1. Sample and Sudy Design. To examine the relationship between social capital and neighborhood design, a crosssectional survey of adults $(n=339)$ was undertaken in April 2002. The sample of residents was randomly selected from three Perth suburbs ( $n=119$ for each suburb) whose inclusion in the study was based on differentiated street network and connectivity patterns commonly used in planning in Australia and USA [29]. These distinguish suburbs in metropolitan Perth and are typically referred to as traditional, conventional, and hybrid as illustrated in Table 1. An area with a high level of connectivity or permeability is considered a more walkable suburb, as it provides direct routes between destinations as well as choices of routes between destinations. Of the street design patterns in Table 1, the Traditional suburb has the highest connectivity, whilst the nongrid layout and culde-sacs characterizing conventional suburbs render them as having the lowest connectivity. Hybrid suburbs, as the name implies, lies between traditional and conventional in terms of connectivity.

The three study suburbs represented each of the street network and connectivity patterns (traditional, conventional, hybrid) and also differed on factors such as mixed land use and availability of community facilities. Distinguishing neighborhood design characteristics of the three study suburbs are summarized in Table 1, which also includes summary information about the availability of key facilities and public amenities within each suburb (such as parks, schools, and shops).

The selected suburbs were matched on socioeconomic status to control for the potential influence of socioeconomic variations on suburb characteristics and residents. They all fell within the lower-mid socio-economic ranking on the Australian Bureau of Statistics [30].

The telephone survey was undertaken by the University of Western Australian Survey Research Centre using the CATI (computer-assisted telephone information) system, and a randomized sampling method was used that balanced the chances of selecting a mix of gender and age groups. Eligibility for the study included being 18 years of age or older, and living in the current suburb for at least 12 months. The response rate was $34.3 \%$. For each of the study suburbs, there were 113 survey respondents (total $n=339$ ). The age distribution of participants was comparable with that of the Western Australian population overall [31], but men were slightly underrepresented (40\%).
3.2. Measures. The survey instrument included items that measured social capital and perceptions of the physical suburban environment, including adequacy of local facilities, feelings of safety, and perceived incivilities (see Table 2). The instrument incorporated or adapted items from previous studies where possible, with new original items also developed based on the literature and formative qualitative research. The items were subjected to test retest reliability, and were found to have moderate-to-excellent test retest reliability. Intraclass correlation coefficients (ICCs) for scales ranged from 0.74 to 0.92 .

Survey items were factor analyzed and a number of scales created-these related to conceptual elements of social capital (e.g., trust, reciprocity) incivilities feelings of safety, and adequacy of local facilities. These scales and their component items and key factorial structures are summarized in Table 2. Further factor analysis produced an overall social capital scale, comprising a composite of subscales for trust, civic engagement, community concern, reciprocity, friendliness, support, and social networks, with possible scores ranging between 12 and 89. Demographic questions included home ownership, dependent children, employment status, level of education, age, and gender.

3.3. Data Analysis. Suburb differences in the mean social capital score were examined using one-way analysis of variance (ANOVA). To adjust for demographic and confounding factors, multivariate analysis was undertaken using logistic regression for variables with binary outcome measures and ordinal logistic regression (proportional odds model) for ordinally distributed variables. The multivariate analysis adjusted for age, gender, education, children living at home (defined as children under the age of 18 living at home), type of dwelling (house, duplex/unit, townhouse, and apartment/flat), and years living in suburb. Ordinal regression enabled analysis of associations with suburb as an independent variable, as well as providing an estimate of effect (odds ratio) [33]. Ordinal regression as a proportional odds model was considered appropriate for the conceptual nature of the social capital scale, which provides a ranking of scores relative to each other, but without necessarily an absolute or equal difference between varying scores $[33,34]$. The ordinal regression was conducted using both the Traditional and Hybrid suburb designs as separate reference categories, to include all comparative permutations of suburb pairs. Continuous dependent variables were recoded into tertiles for the purposes of the ordinal regression.

\section{Results}

Associations between suburb design and social capital and between social capital and perceptions of the neighborhood environment are described below.

4.1. Neighborhood Street Network Design and Layout and Social Capital. It was hypothesized from the literature that the traditional neighborhood design (characterized by grid street networks) would provide the most walkable 
TABLE 1: Characteristics of study suburbs.

\begin{tabular}{|c|c|c|c|}
\hline Suburb & Conventional & Traditional & Hybrid \\
\hline \multicolumn{4}{|l|}{ Suburb street network } \\
\hline & $\begin{array}{l}\text { Cul-de-sac and curved } \\
\text { layout }\end{array}$ & Predominantly grid layout & Mix of grid and cul-de-sacs \\
\hline Suburb description & $\begin{array}{l}\text { Grid-style street network, } \\
\text { with a variety of shops and } \\
\text { other services located } \\
\text { primarily on a major } \\
\text { central road. }\end{array}$ & $\begin{array}{l}\text { Street network combined traditional } \\
\text { grid system with circular roads and } \\
\text { cul-de-sacs. A large shopping mall } \\
\text { complex present but not centrally } \\
\text { located, other community facilities are } \\
\text { generally scattered throughout the } \\
\text { suburb. }\end{array}$ & $\begin{array}{l}\text { Cul-de-sac street network typical of } \\
\text { urban sprawl and low residential } \\
\text { density. Many community facilities } \\
\text { were located centrally but also a } \\
\text { dispersion of several small shopping } \\
\text { complexes. }\end{array}$ \\
\hline Suburb area $(\mathrm{km})$ & 8.98 & 4.94 & 5.07 \\
\hline Number of cul-de-sacs & 304 & 39 & 119 \\
\hline $\begin{array}{l}\text { Number of } 3 \text { way or greater } \\
\text { intersections }\end{array}$ & 448 & 134 & 267 \\
\hline Intersections per sq. $\mathrm{km}^{1}$ & 49.89 & 39.27 & 52.66 \\
\hline $\begin{array}{l}\text { Density of cul-de-sacs per } \\
\text { sq. } \mathrm{km}^{2}\end{array}$ & 33.85 & 7.89 & 23.47 \\
\hline Dwelling type & $\begin{array}{l}\text { Predominantly single } \\
\text { detached houses }\end{array}$ & $\begin{array}{l}\text { Number of high rise apartments, along } \\
\text { with separate houses }\end{array}$ & $\begin{array}{c}\text { Predominantly single detached } \\
\text { houses }\end{array}$ \\
\hline Bakeries, newsagents, deli & 8 & 7 & 5 \\
\hline $\begin{array}{l}\text { Retail-essential services } \\
\text { (e.g., hairdressers, petrol } \\
\text { stations, banks, and } \\
\text { launderettes) }\end{array}$ & 13 & 16 & 19 \\
\hline Bus stops & 91 & 73 & 71 \\
\hline Primary schools & 4 & 1 & 3 \\
\hline Parks & 22 & 10 & 22 \\
\hline
\end{tabular}

${ }^{1}$ Intersections per sq. km: number of $\geq 3$ way intersections/area.

${ }^{2}$ Cul-de-sacs per sq. km: number of cul-de-sacs/area.

environment, and that this in turn would contribute to higher social capital through opportunities for residents to meet and engage in their suburb. However, when the mean social capital scores were compared between suburbs (using ANOVA), conventional suburb residents had a higher mean social capital score (60.30 $\pm 8.48 \mathrm{SD})$ compared with Hybrid $(55.73 \pm 8.24 \mathrm{SD})$ and Traditional (55.25 $\pm 9.46 \mathrm{SD})$ suburb residents $(P<0.001)$. In the ordinal regression analysis, both Traditional and Conventional suburb residents were almost twice as likely or more to score higher on the social capital scale than Hybrid suburb residents (see Table 3).

\subsection{Experiences and Perceptions of the Neighborhood Environ-} ment and Social Capital. It was hypothesized that negative experiences and perceptions of the physical neighborhood environment would be negatively associated with social capital. Several aspects of the perceived physical and social environment were assessed:adequacy of facilities; presence of incivilities (e.g., graffiti, unkempt gardens, and crime); and feelings of safety.

The adequacy of facilities scale assessed respondents' satisfaction with a range of fifteen types of facilities within their suburb, including parks, shops, and medical services and activities for young people. The ordinal regression model showed that compared with residents in the Hybrid suburb, Conventional suburb residents were nearly twice as likely to perceive local facilities as more adequate (OR 1.83; 95\% CI 1.12-2.99), as were Traditional suburb residents (see Table 3 ). Traditional suburb residents were also more likely to do so, but this did not reach statistical significance. Greater satisfaction with local amenities was also associated with social capital overall, with those who rated adequacy of 


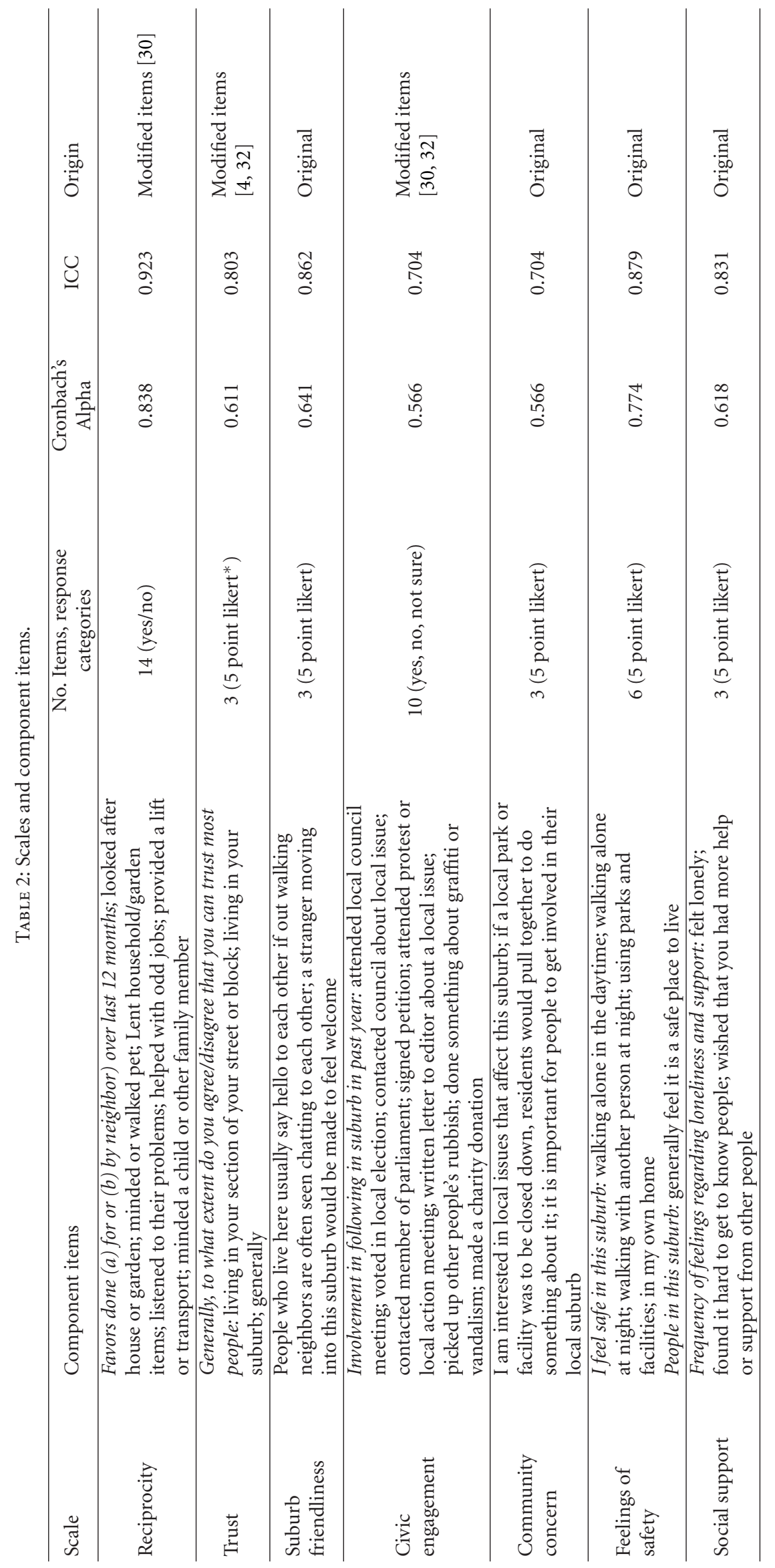




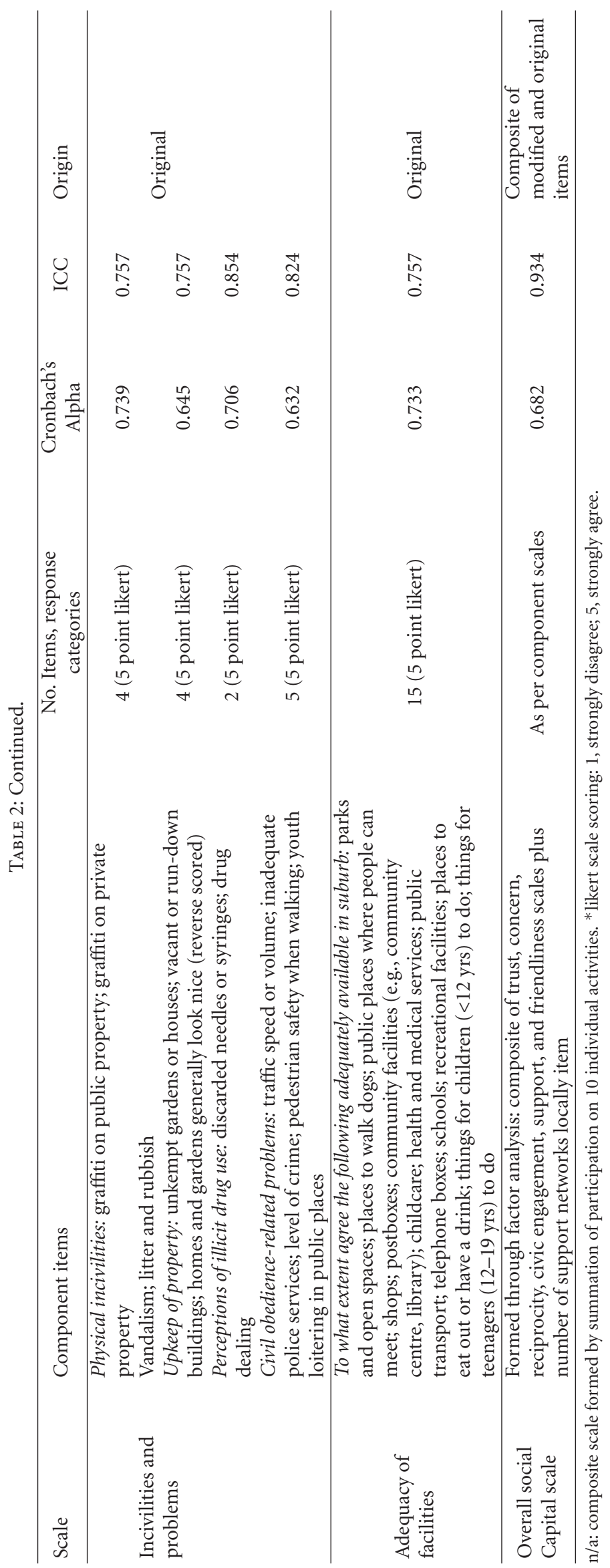


TABLE 3: Ordinal odds ratios associating social capital, adequacy of facilities, and safety with suburb design.

\begin{tabular}{lccc}
\hline & Suburb design & Adjusted OR $^{\mathrm{a}}$ & $P$ value \\
\hline \multirow{3}{*}{ Social capital } & Hybrid $^{\mathrm{b}}$ & 1.00 & \\
& Conventional & $2.29(1.39-3.78)$ & 0.001 \\
& Traditional & $1.86(1.02-3.40)$ & 0.044 \\
\hline & Hybrid $^{\mathrm{b}}$ & 1.00 & \\
Perceived adequacy of facilities & Conventional & $1.83(1.12-2.99)$ & 0.015 \\
& Traditional & $1.46(0.81-2.64)$ & 0.210 \\
\hline
\end{tabular}

${ }^{a}$ Adjusted for age, gender, education, children living at home, type of dwelling, and years in suburb. ${ }^{b}$ Reference suburb.

facilities in their suburbs as low, only half as likely to have a high social capital score (OR 0.53; 95\% CI 0.32-0.89).

On the feelings of safety scale comprising questions relating to how safe respondents felt in their suburb in various circumstances, there were significant differences between all three suburbs in the ordinal regression analysis. (see Table 3). Compared with residents in the Hybrid suburb, Conventional suburb residents were more than four and half times as likely to have a higher feelings of safety score (OR 4.63; 95\% CI 2.74-7.81), while Traditional suburb residents were twice as likely to do so (OR 2.15; 95\% CI 1.68-3.96).

Four incivility scales were formed through factor analysis from items relating to the extent to which various issues (e.g., graffiti, unkempt gardens, and crime) were problematic in respondents' suburbs. Suburb differences were observed for property upkeep, civil obedience, and perceptions of drug use, but not for physical incivilities. Conventional suburb residents were six to seven times less likely to rate property upkeep as a problem than Traditional and Hybrid suburb residents, respectively. Both Conventional and Traditional suburb residents differed significantly from Hybrid suburb residents on the civil obedience scale, with Hybrid suburb residents around twice as likely traditional residents to perceive civil obedience as problematic within their suburb (see Table 4). Illicit drug use was less likely to be perceived as a problem by Conventional suburb residents, compared with residents living in the Hybrid suburb (OR 0.40 95\% CI 0.24 $0.66)$.

Further analysis was undertaken to examine associations between social capital and perceptions of safety and incivilities across the three suburbs. Low perceived safety and suburban incivilities in the form of unkempt houses, gardens, and public spaces were negatively associated with social capital (see Table 5). However, other physical incivilities such as graffiti, vandalism, and civil obedience problems were not associated with social capital in the multivariate model.

Higher feelings of safety corresponded to higher levels of social capital, with the odds of a high social capital score more than two and a half times higher for residents with a high feelings of safety score (OR 2.64 95\% CI 1.49-4.68).

\section{Discussion}

Based on previous research and New Urbanism principles, it was hypothesized that the Traditional neighborhood design (characterized by grid street networks) would provide a more walkable environment, which in turn would promote neighborly interactions and the development of social capital $[19,23]$. Our findings in relation to this first hypothesis were mixed. On the overall measure of social capital and contrary to our hypothesis, residents in the suburb with the greatest number of cul-de-sacs and lowest connectivity (i.e., the Conventional suburb), generally had the highest social capital. However, Traditional suburb (grid network design) residents reported higher levels of social capital than those living in the Hybrid suburb that was characterized by a convoluted street network, cul-de-sacs, and fewer proximate destinations and amenities.

Prima facie, therefore, our results do not seem to support the hypothesis that suburbs with more connected street networks will have higher social capital, but other findings from the study offer some potential elucidation. For example, synthesis of the data indicates that while the Traditional suburb has a grid design and more walkable facilities and public amenities, its residents reported lower levels of trust, feelings of safety and neighborhood friendliness, and more perceived problems relating to upkeep and drug use. The Traditional suburb also had a greater preponderance of flats, which may also have had a mitigating influence on sense of community and social capital, due to the more negative perceptions of "living in flats" and stigmatizing of public housing that can occur $[35,36]$. The qualitative formative research underpinning this study [37] identified some negative stereotyping of "flats" in relation to sense of community, and concerns about safety and incivilities were more pronounced in the focus group discussions with residents in the Traditional suburb.

In this study, social capital was lowest in the Hybrid suburb, whose residents consistently scored less positively on most of the scales included in the analysis. This supports our contention that it is the combination of neighborhood 
TABLE 4: Ordinal odds ratios associating incivilities with suburb design.

\begin{tabular}{|c|c|c|c|c|c|c|}
\hline \multirow[b]{2}{*}{ Suburb } & \multicolumn{2}{|c|}{ Upkeep } & \multicolumn{2}{|c|}{ Civil obedience } & \multicolumn{2}{|c|}{ Illicit drug use } \\
\hline & Adjusted OR* & $P$ value & Adjusted $\mathrm{OR}^{\mathrm{a}}$ & $P$ value & Adjusted OR* & $P$ value \\
\hline Hybrid $^{b}$ & 1.00 & & 1.00 & & 1.00 & \\
\hline Conventional & $0.14(0.08-0.25)$ & $<0.001$ & $0.40(0.24-0.66)$ & $<0.001$ & $0.40(0.24-0.66)$ & $<0.001$ \\
\hline Traditional & $0.92(0.49-1.69)$ & 0.777 & $0.51(0.28-0.93)$ & 0.029 & $0.65(0.36-1.20)$ & 0.170 \\
\hline
\end{tabular}

${ }^{a}$ Adjusted for age, gender, education, children living at home, type of dwelling, and years in suburb. ${ }^{b}$ Reference suburb.

TABLE 5: Ordinal odds ratios associating social capital with neighborhood characteristics.

\begin{tabular}{lccc}
\hline Neighborhood characteristic & Adjusted OR & $95 \%$ CI & $P$ value \\
\hline Civil obedience problems & 1.37 & $(0.80-2.34)$ & $(0.25-1.46)$ \\
Physical incivilities & 1.38 & $(1.11-4.05)$ & 0.245 \\
Upkeep of property & 2.12 & $(0.99-2.78)$ & 0.220 \\
Illicit drug use & 1.66 & $(1.49-4.68)$ & 0.023 \\
Feelings of safety & 2.64 & $(0.32-0.89)$ & 0.550 \\
Satisfaction with local amenities & 0.53 & & 0.001 \\
\hline
\end{tabular}

${ }^{a}$ Adjusted for age, gender, education, children living at home, type of dwelling, and years in suburb.

characteristics that influences social capital: in the case of the Hybrid suburb, not only did it have relatively poor street connectivity and less proximate destinations and amenities, but its residents were also least likely to feel safe and most likely to perceive property upkeep, civil obedience, and illicit drug use as problematic.

The findings of the study generally supported our second hypothesis: negative experiences and perceptions of the physical neighborhood environment can detrimentally impact on social capital. In the multivariate model, low perceived safety and suburban incivilities in the form of unkempt houses, gardens, and public spaces were negatively associated with social capital, as were perceived drug use problems, although the latter did not reach statistical significant at the 0.05 level. Interestingly, while suburbs did not differ significantly in relation to more traditionally measured incivilities such as graffiti, litter, and vandalism, there were marked differences relating to property upkeep, which has been alluded to in the literature as a more applicable marker of physical incivilities in suburban as opposed to urban neighborhoods [38]. Indeed, residents in the Conventional suburb which had the highest social capital were more likely to feel safe and reported fewer problems relating to property upkeep than both Traditional and Hybrid suburb residents.

Across all suburbs we found that higher perceptions of neighborhood problems (such as incivilities) corresponded to lower feelings of safety among surveyed residents. This is congruent with other studies associating negative environmental cues (both perceived and actual) with fear of crime $[15,39,40]$ and social withdrawal $[40]$. This may be one of the mechanisms through which negative perceptions of the neighborhood environment may influence social capital. Our mixed findings relating to the Traditional suburb support this contention, whereby perceptions of greater problems about upkeep and drug use, and lower feelings of safety and trust may have countered some of the hypothesized positive impacts of the grid street network design on neighborhood interactions, involvement, and social capital. It seems plausible that neighborhood safety may influence the formation of social capital via effects on both perceptions of walkability $[24,41]$, and on the extent to which people feel safe to go walking or visit local parks or facilities [28]. This premise merits further research, ideally of a longitudinal nature to further understanding of the causal pathways and direction, which is often difficult to disentangle in social capital research.

Social capital was also investigated in relation to perceived adequacy of local facilities. Conventional suburb residents were more likely to perceive local facilities as adequate, and overall social capital was associated with greater satisfaction with the adequacy of local facilities. However, the findings suggest that the adequacy of facilities was not simply a reflection of availability and access, as there was marked variability between suburbs on the perceived adequacy of specific facilities (such as parks and places to walk), for which there was little objective difference. For example, despite more favorable perceptions of adequacy among residents, the Conventional suburb had a similar number of parks and shops to the other suburbs, but fewer entertainment options and public facilities. This resonates with other studies that have investigated the relative influence of quality versus quantity of neighborhood amenities. In relation to mental health, for example, the quality of parks and public open space has been found to be more important than quantity, both when quality is measured objectively [42] or by resident perceptions [43-45]. Similarly, the mere presence of "public spaces" within a community does not guarantee their use, with quality and aesthetics of such spaces an important determinant of how they are perceived and used by residents [46]

More broadly, it is possible that the general tenor of satisfaction with suburban life (as measured by social capital and sense of community indicators) shapes attitudes towards features of that suburb as well as propensity for 
involvement, and this may explain the differences observed between suburbs in this study. This is congruent with the notion of a "virtuous circle" that has been postulated in relation to social capital [47]. For example, people out and about walking, well maintained private and public property, and seeing neighbors chatting and interacting with each other can precipitate "like" behaviour, shape norms, and engender positive sense of community type sentiments among residents. While the spiraling of negative environmental and neighborhood effects (often referred to as the broken windows hypothesis [48] is most commonly referred to in the literature and in the popular media, a positive spiraling of favorable neighborhood characteristics in the form of a "virtuous circle" seems just as plausible and merits further attention in both research and local community interventions.

5.1. Limitations and Implications for Future Research. This study was inspired by Leyden [19] who suggests that more walkable neighborhoods increase social capital. However, unlike Leyden [19] it used an objective measure of walkability based on street network connectivity. Clearly neighborhood walkability is more complex than this, and future studies might consider other neighborhood attributes including mixed use planning and population density. For example, in this study the Traditional suburb had more flats and higher-density housing than the other two suburbs, which may have mitigated the influence of the more walkable neighbourhood design on social capital due to more negative perceptions of "living in flats" and stigmatizing of public housing that can occur $[35,36]$ and that was detected in the focus groups undertaken as part of the formative research for this study [37]. Although type of dwelling was adjusted for in the analysis, suburb variability in residential density and housing type have implications for further studies and have rarely been considered in social capital research to date.

The study was also limited to three suburbs, and, as with all such restricted samples, the limited generalizability of findings is acknowledged. Although the sample size was not large $(n=339)$, it was designed to have sufficient power for the purposes of the analysis undertaken. The potential loss of power through conversion of continuous variables to tertiles in the ordinal regression analysis is also acknowledged [49]. While it is recognised that a smaller sample size contributes to larger confidence intervals when adjusted for multiple confounding factors [50], the adjusted models strengthen inferences that can be drawn about the independent influence of key variables. While this study adjusted for individual level demographics and residency characteristics as well as suburb design, a larger study would have permitted the use of more sophisticated multilevel modeling techniques for clustered data (multiple persons within a single neighborhood). This would have strengthened the methodology and enabled area level effects to be studied. Nevertheless, the analyses were adjusted for seven factors (age, gender, education, children living at home, type of dwelling, suburb, and years lived in suburb), and very few published social capital studies have adjusted for this number or range of potential confounders. We did not adjust for ethnicity which has been considered in some other social capital studies, but we did confirm that the three suburbs were reasonably comparable in this regard.

The validity and reliability of the measures were generally acceptable, but some of the lower reliability scores were a study limitation. Nevertheless, it is one of the few published social capital studies to even have assessed the reliability of measures, and future researchers in this domain are encouraged to give greater attention to assessing and reporting on validity and reliability.

The response rate of $34.3 \%$ is a limitation although it is within the range of those obtained in similar telephone surveys $[32,51,52]$. While poor response rates can reduce the external validity of findings, validity is strengthened if the sample is representative of the population from which it is drawn [24]; the study sample was found to correspond the Western Australian population on a number of key demographic, and, residency characteristics and where it did not, adjustment was made in the analysis.

In this study the associations between social capital and socioenvironmental traits were examined separately, but future research could consider the use of path analysis [14], or structural equation modeling [53] to more explicitly investigate mediating effects.

As with many social capital studies, the cross-sectional design precludes causal inferences being directly drawn. Nonetheless, cross-sectional studies contribute to hypothesis generation related to the mechanisms through which social capital and neighborhood characteristics that might be related and that can then be further tested within a longitudinal design.

\section{Conclusion}

The mixed findings of this study highlight the complexities of designing studies examining area differences in social capital related to neighborhood walkability and the importance of considering neighborhood characteristics in total, rather than in isolation. Our findings suggest that the built environment may influence social capital, at both a real and perceived level. Street connectivity, the presence of walkable destinations, and attendance to visible problems and incivilities may impact on social capital formation and maintenance. These findings are important given trends towards intensifying land use in residential areas, and highlight the need to locate higher-density housing in areas with more amenities and attend to maintenance of the local area. However, just as important is the way in which perceptions of a neighborhood's physical and social environment are formed and interact. For example, unkempt gardens and grounds not only influence neighborhood aesthetics, but may convey messages about local norms, safety, and trust. This resonates with the "broken windows" hypothesis [48] but warrants further research as a postulated link between neighborhood characteristics and social capital.

Similarly, the provision of social and recreational facilities goes beyond actual service provision but may contribute 
to perceptions and the extent to which people feel connected with their community. While some elements of the environments in which people live are fixed, many local features are socially constructed and can be changed, improved, added, or better used for health or social capital gain. Herein lie opportunities for future interventions to improve health through improving the physical and/or social environments in which people live, work, and play. From a research perspective, greater advantage should be taken of "natural experiments" [54], whereby the impact of infrastructure, planning or policy changes within neighborhoods can be observed or evaluated to assess their impact on health and social wellbeing outcomes.

As populations grow and increasingly congregate in urbanized cities, new developments or the revitalization of existing suburbs present valuable opportunities to monitor and evaluate any positive or negative impacts on the social fabric and health of local residents.

\section{Acknowledgments}

The first author is currently supported by a Healthway (Western Australian Health Promotion Foundation) Senior Research Fellowship and the second author by an Australian NHMRC Principal Research Fellowship.

\section{References}

[1] D. Cohen and L. Prusak, In Good Company. How Social Capital Makes Organisations Work, Harvard Business School Press, Boston, Mass, USA, 2001.

[2] F. Baum, "Social capital: is it good for your health? Issues for a public health agenda," Journal of Epidemiology and Community Health, vol. 53, no. 4, pp. 195-196, 1999.

[3] P. Hawe and A. Shiell, "Social capital and health promotion: a review," Social Science and Medicine, vol. 51, no. 6, pp. 871$885,2000$.

[4] I. Kawachi and B. P. Kennedy, "The relationship of income inequality to mortality: does the choice of indicator matter?" Social Science and Medicine, vol. 45, no. 7, pp. 1121-1127, 1997.

[5] B. Edwards and M. W. Foley, "Social capital and the political economy of our discontent," American Behavioral Scientist, no. 5, pp. 669-678, 1997.

[6] R. D. Putnam, "E pluribus unum: diversity and community in the twenty-first century the 2006 johan skytte prize lecture," Scandinavian Political Studies, vol. 30, no. 2, pp. 137-174, 2007.

[7] P. Katz, The New Urbanism: Toward an Architecture of Community, McGraw-Hill, New York, NY, USA, 1994.

[8] A. McCulloch, "An examination of social capital and social disorganisation in neighbourhoods in the British household panel study," Social Science and Medicine, vol. 56, no. 7, pp. 1425-1438, 2003.

[9] S. V. Subramanian, K. A. Lochner, and I. Kawachi, "Neighborhood differences in social capital: a compositional artifact or a contextual construct?" Health and Place, vol. 9, no. 1, pp. 3344, 2003.

[10] S. Macintyre, A. Ellaway, and S. Cummins, "Place effects on health: how can we conceptualise, operationalise and measure them?" Social Science and Medicine, vol. 55, no. 1, pp. 125-139, 2002.

[11] M. T. Hyyppä and J. Mäki, "Social participation and health in a community rich in stock of social capital," Health Education Research, vol. 18, no. 6, pp. 770-779, 2003.

[12] S. Macintyre and A. Ellaway, "Neighbourhood cohesion and health in socially contrasting neighbourhoods: implications for the social exclusion and public health agendas," Health Bulletin, vol. 58, no. 6, pp. 450-456, 2000.

[13] S. Saegert and G. Winkel, "Social Capital and the Revitalization of New York City's Distressed Inner-City Housing," Housing Policy Debate, vol. 9, no. 1, pp. 17-60, 1998.

[14] A. M. Ziersch, F. E. Baum, C. MacDougall, and C. Putland, "Neighbourhood life and social capital: the implications for health," Social Science and Medicine, vol. 60, no. 1, pp. 71-86, 2005.

[15] D. M. Chavis and A. Wandersman, "Sense of community in the urban environment: a catalyst for participation and community development," American Journal of Community Psychology, vol. 18, no. 1, pp. 55-81, 1990.

[16] D. D. Perkins, J. W. Meeks, and R. B. Taylor, "The physical environment of street blocks and resident perceptions of crime and disorder: implications for theory and measurement," Journal of Environmental Psychology, vol. 12, no. 1, pp. 21-34, 1992.

[17] A. Sooman and S. Macintyre, "Health and perceptions of the local environment in socially contrasting neighbourhoods in glasgow," Health and Place, vol. 1, no. 1, pp. 15-26, 1995.

[18] P. Bruce, "New Urbanism and the generation of social capital: evidence from Orenco Station," National Civic Review, vol. 91, no. 3, pp. 245-255, 2002.

[19] K. M. Leyden, "Social capital and the built environment: the importance of walkable neighbourhoods," American Journal of Public Health, vol. 93, no. 9, pp. 1546-1551, 2003.

[20] T. Sander, "Social capital and New Urbanism: leading a civic horse to water?" National Civic Review, vol. 91, no. 3, pp. 213234, 2002.

[21] J. Grant, Planning the Good Community: New Urbanism in Theory and Practice, Taylor \& Francis, New York, NY, USA, 2006.

[22] S. Deitrick and C. Ellis, "New urbanism in the inner city: a case study of Pittsburgh," Journal of the American Planning Association, vol. 70, no. 4, pp. 426-442, 2004.

[23] H. Lund, "Testing the claims of new urbanism: local access, pedestrian travel, and neighboring behaviors," Journal of the American Planning Association, vol. 69, no. 4, pp. 414-429, 2003.

[24] H. Lund, "Pedestrian environments and sense of community," Journal of Planning Education and Research, vol. 21, no. 3, pp. 301-312, 2002.

[25] L. Wood and H. Christian, "Dog walking as a catalyst for strengthening the social fabric of the community," in The Health Benefits of Dog Walking for People and Pets. Evidence \& Case Studies: West Lafayette, R. Johnson, A. Beck, and S. McCune, Eds., Purdue University Press, 2011.

[26] Infrastructure Australia and Major Cities Uni, State of Australian Cities 2010, Commonwealth of Australia, Canberra, Australia, 2010.

[27] G. Wilson-Doenges, "An exploration of sense of community and fear of crime in gated communities," Environment and Behavior, vol. 32, no. 5, pp. 597-611, 2000.

[28] L. Wood, T. Shannon, M. Bulsara, T. Pikora, G. McCormack, and B. Giles-Corti, "The anatomy of the safe and social 
suburb: an exploratory study of the built environment, social capital and residents' perceptions of safety," Health and Place, vol. 14, no. 1, pp. 15-31, 2008.

[29] S. Handy, R. Paterson, and K. Butler, "Planning for street connectivity: getting from here to there," Planning Advisory Service Report No. 515, American Planning Association, Chicago, Ill, USA, 2003.

[30] C. Modra, F. Baum, R. Cooke, C. Murray, R. Bush, and E. Cox, "Exploring Social Capital-levels of participation, trust and health in a suburban region of Adelaide, South Australia," in 30th Annual Public Health Association Conference, Hobart, Australia, 1998.

[31] ABS, 2001 Census Basic Community Profile and Snapshot: Western Australia, Australian Bureau of Statistics, Canberra, Australia, 2002.

[32] Saguaro Seminar: Civic Engagement in America, Social Capital Community Benchmark Survey, John F. Kennedy School of Government, Harvard University, Cambridge, Mass, USA, 2000.

[33] D. Kleinbaum and M. Klein, Logistic Regression: A SelfLearning Text, Springer, New York, NY, USA, 2002.

[34] C. V. Ananth and D. G. Kleinbaum, "Regression models for ordinal responses: a review of methods and applications," International Journal of Epidemiology, vol. 26, no. 6, pp. 13231333, 1997.

[35] D. Halpern, Mental Health and the Built Environment: More Than Bricks and Mortar? Taylor \& Francis, London, UK, 1995.

[36] A. Hastings, "Stigma and social housing estates: beyond pathological explanations," Journal of Housing and the Built Environment, vol. 19, no. 3, pp. 233-254, 2004.

[37] L. Wood, Social capital, mental health and the environments in which people live [Ph.D. thesis], School of Population Health. The University of Western Australia, Perth, Australia, 2005.

[38] B. B. Brown, D. D. Perkins, and G. Brown, "Crime, new housing, and housing incivilities in a first-ring suburb: multilevel relationships across time," Housing Policy Debate, vol. 15, no. 2, pp. 301-345, 2004.

[39] S. Foster, B. Giles-Corti, and M. Knuiman, "Neighbourhood design and fear of crime: a social-ecological examination of the correlates of residents' fear in new suburban housing developments," Health and Place, vol. 16, no. 6, pp. 1156-1165, 2010.

[40] D. D. Perkins and R. B. Taylor, "Ecological assessments of community disorder: their relationship to fear of crime and theoretical implications," American Journal of Community Psychology, vol. 24, no. 1, pp. 63-107, 1996.

[41] K. A. Lochner, I. Kawachi, R. T. Brennan, and S. L. Buka, "Social capital and neighborhood mortality rates in Chicago," Social Science and Medicine, vol. 56, no. 8, pp. 1797-1805, 2003.

[42] J. Francis, L. J. Wood, M. Knuiman, and B. Giles-Corti, "Quality or quantity? Exploring the relationship between Public Open Space attributes and mental health in Perth, Western Australia," Social Science and Medicine, vol. 74, no. 10, pp. 1570-1577, 2012.

[43] T. Bjerke, T. Østdahl, C. Thrane, and E. Strumse, "Vegetation density of urban parks and perceived appropriateness for recreation," Urban Forestry and Urban Greening, vol. 5, no. 1, pp. 35-44, 2006.

[44] M. J. Licari, W. McLean, and T. W. Rice, "The condition of community streets and parks: a comparison of resident and nonresident evaluations," Public Administration Review, vol. 65, no. 3, pp. 360-368, 2005.
[45] G. Sanesi and F. Chiarello, "Residents and urban green spaces: the case of Bari," Urban Forestry and Urban Greening, vol. 4, no. 3-4, pp. 125-134, 2006.

[46] N. Pasaogullari and N. Doratli, "Measuring accessibility and utilization of public spaces in Famagusta," Cities, vol. 21, no. 3, pp. 225-232, 2004.

[47] R. D. Putnam, "Using social capital to help integrate planning theory, research, and practice," Journal of the American Planning Association, vol. 70, no. 2, pp. 142-145, 2004.

[48] J. Wilson and G. Kelling, "Broken windows: the police and neighborhood safety," Atlantic Monthly, vol. 249, no. 3, pp. 29$38,1982$.

[49] A. B. Taylor, S. G. West, and L. S. Aiken, "Loss of power in logistic, ordinal logistic, and probit regression when an outcome variable is coarsely categorized," Educational and Psychological Measurement, vol. 66, no. 2, pp. 228-239, 2006.

[50] C. E. Pollack and O. Von Dem Knesebeck, "Social capital and health among the aged: comparisons between the United States and Germany," Health and Place, vol. 10, no. 4, pp. 383$391,2004$.

[51] M. S. O’Brien, C. A. Burdsal, and C. A. Molgaard, "Further development of an Australian-based measure of social capital in a US sample," Social Science and Medicine, vol. 59, no. 6, pp. 1207-1217, 2004.

[52] W. Stone and J. Hughes, "Social capital: empirical meaning and measurement validity," Research Paper No. 27, Australian Institute of Family Studies, Melbourne, Australia, 2002.

[53] L. C. Mâsse, C. Dassa, L. Gauvin, B. Giles-Corti, and R. Motl, "Emerging measurement and statistical methods in physical activity research," American Journal of Preventive Medicine, vol. 23, no. 2, pp. 44-55, 2002.

[54] M. Petticrew, S. Cummins, C. Ferrell et al., "Natural experiments: an underused tool for public health?" Public Health, vol. 119, no. 9, pp. 751-757, 2005. 


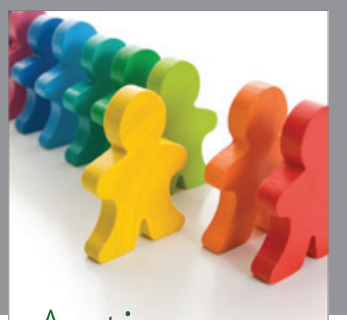

Autism

Research and Treatment
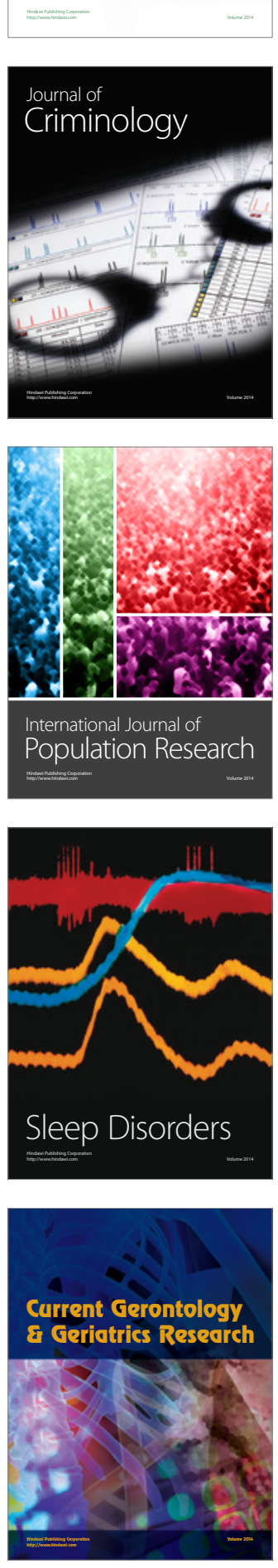
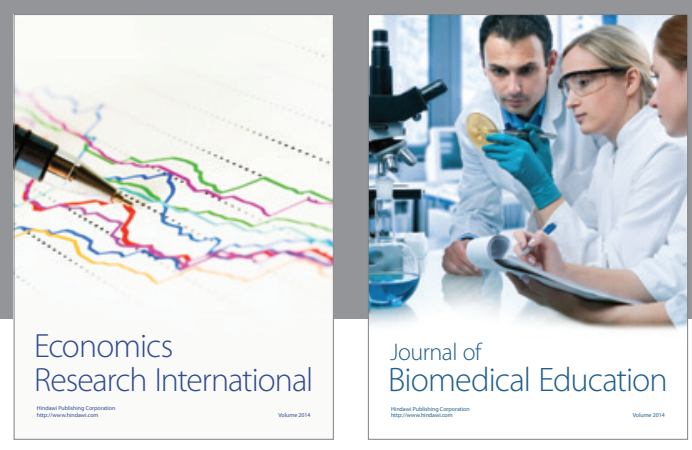

Journal of

Biomedical Education

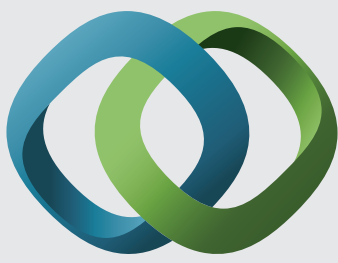

\section{Hindawi}

Submit your manuscripts at

http://www.hindawi.com
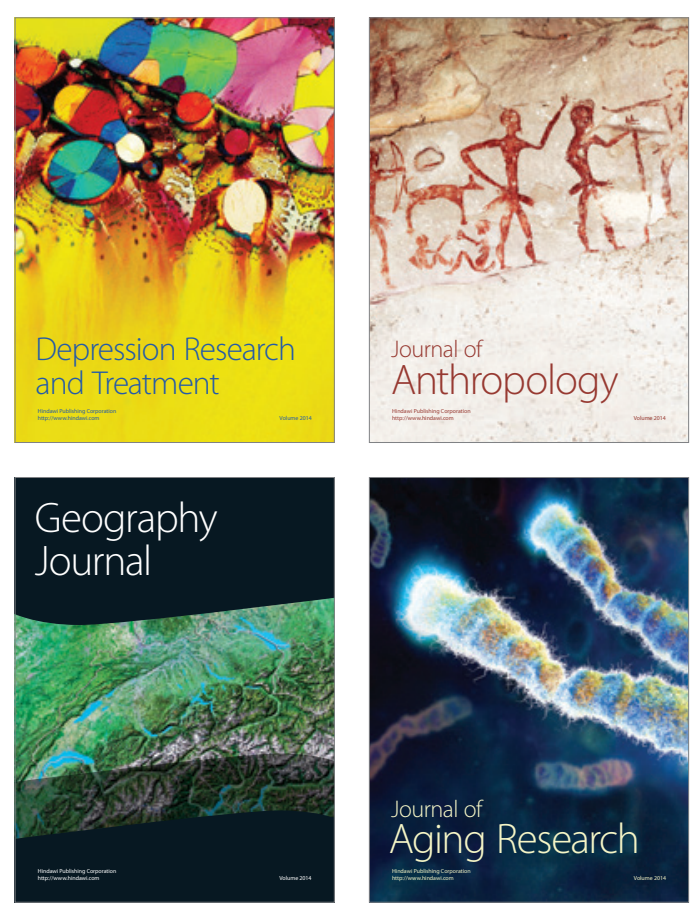

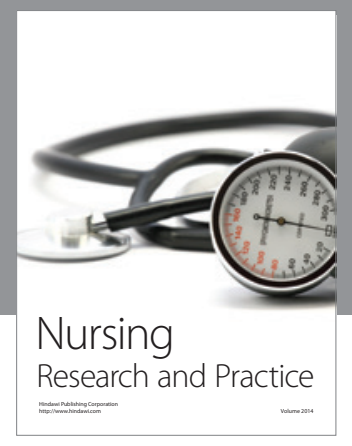

Nursing

Research and Practice

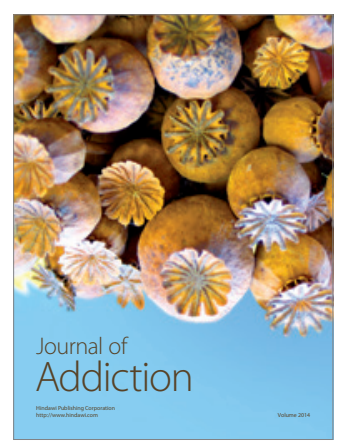

Child Development

Research

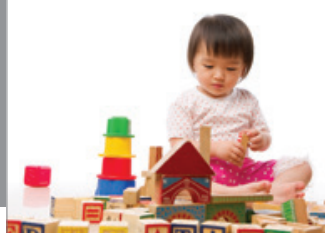

迥
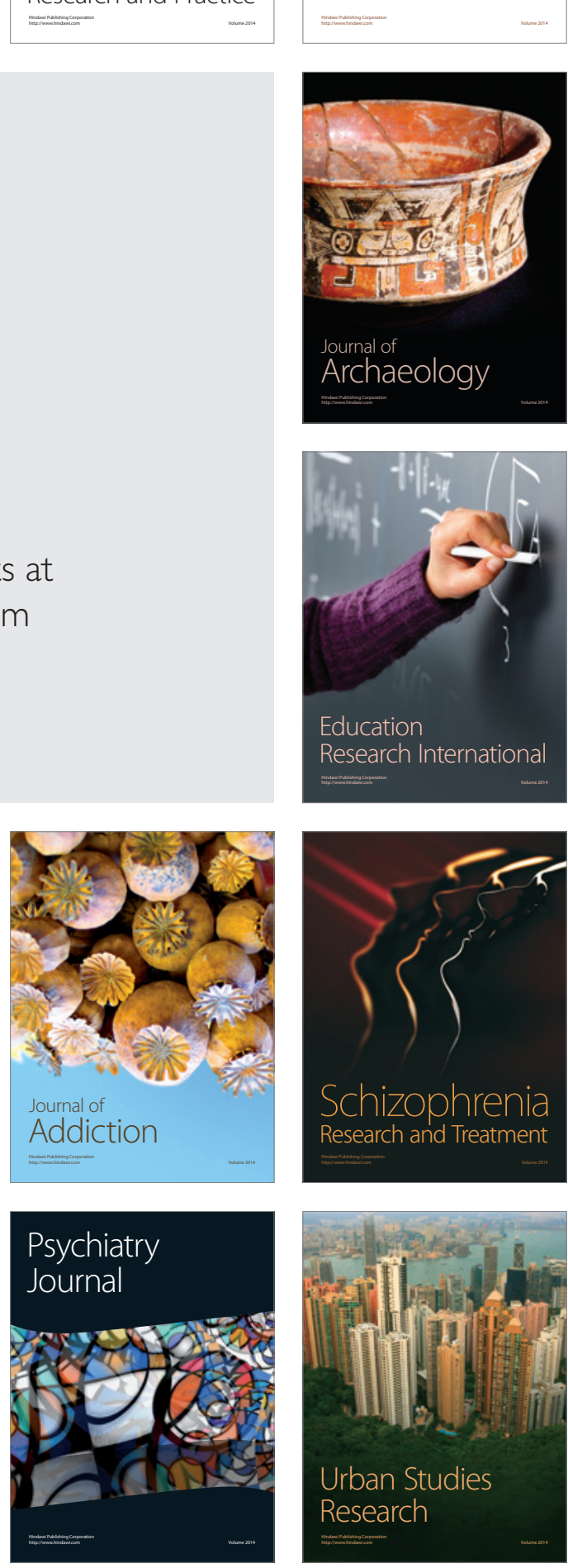